\title{
ESTIMATIVA DA ACIDEZ POTENCIAL PELO PH SMP EM SOLOS DO SEMI-ÁRIDO DO NORDESTE BRASILEIRO(1)
}

\author{
C. A. SILVA(2), M. L. AVELLAR ${ }^{(3)} \&$ A. C. C. BERNARDI (2)
}

\begin{abstract}
RESUMO
Neste estudo avaliou-se a relação entre o teor de H + Al e o pH SMP, visando estabelecer uma equação para estimar a acidez potencial de solos do Semi-Árido do Nordeste Brasileiro. As análises dos teores de H + Al e dos valores de pH SMP foram realizadas em 81 amostras de solo, variando os teores de carbono de 1,8 a $35,6 \mathrm{~g} \mathrm{~kg}^{-1}$ e os de argila de 60 a $590 \mathrm{~g} \mathrm{~kg}^{-1}$. Os resultados demonstraram que a acidez potencial dessas amostras de solo, expressa em $\mathrm{mmol}_{\mathrm{c}} \mathrm{dm}^{-3}$, pode ser estimada pelo valor do pH em solução tampão SMP, por meio da equação de regressão: $H+A I=31,521(p H S M P)^{2}-451,61$ pH SMP $+1625,3\left(R^{2}=0,87 * *\right)$.
\end{abstract}

Termos de Indexação: pH do solo, solução tampão, hidrogênio, alumínio trocável.

SUMMARY: ESTIMATION OF POTENTIAL ACIDITY BY PH SMP IN SOILS FROM NORTHEASTERN BRAZIL

In this study the relationship between the $\mathrm{pH}$ SMP and $\mathrm{H}+\mathrm{Al}$ concentrations was eval uated, in order to establish an equation for estimating thepotential acidity of soils from Northeastern Brazil. The $\mathrm{H}+\mathrm{Al}$ concentration (calcium acetate $0.5 \mathrm{~mol} \mathrm{~L}^{-1}, \mathrm{pH} 7.0$ ) and pH SMP wereanalyzed in 81 soil samples. Soil carbon content ranged from 1.8 to $35.6 \mathrm{~g} \mathrm{~kg}^{-1}$, and clay content varied from 60 to $590 \mathrm{~g} \mathrm{~kg}^{-1}$. The equation $\mathrm{H}+\mathrm{Al}=31.521(\mathrm{pH} \mathrm{SMP})^{2}$ $-451.61 \mathrm{pH}$ SMP $+1625.3\left(\mathrm{R}^{2}=0.87^{* *}\right)$, with $\mathrm{H}+\mathrm{Al}$ in $\mathrm{mmol}_{\mathrm{c}} \mathrm{dm}^{-3}$, provides a good estimation of potential acidity by using the pH SMP.

Index Terms: soil pH, buffer solution, hydrogen, exchangeablealuminum.

(1) Trabal ho financiado pela Embrapa. Recebido para publicação em setembro de 1999 e aprovado em maio de 2000.

(2) Pesquisador da Embrapa Solos. Rua J ardim Botânico, 1024, CEP 22460-000 Rio deJ aneiro (RJ ). E-mail: csilva@cnps.embrapa.br

(3) Química, B.Sc., Embrapa Solos. 


\section{INTRODUÇÃO}

Os componentes da acidez potencial são os íons $\mathrm{H}^{+}$eAl $3^{+}$presentes nas fases sóli ida elíquida do solo. Na maioria dos laboratórios brasileiros de análise de solo, um dos extratores mais usados para avaliar os teores de $\mathrm{H}+\mathrm{Al}$ no solo é o acetato de cálcio $1 \mathrm{~mol} \mathrm{~L}^{-1}(\mathrm{pH}=7,0)$. Esse método de determinação da acidez potencial tem, porém, al gumas limitações, a saber: o ponto deviragem do indicador (fenolftaleína) é de difícil visualização (Pereira et al., 1998); a quantidade de acetato de cál cio gasta por amostra analisada é elevada, sendo bastante alto o preço desse sal de boa qualidade; a adoção desse método implica maior custo e tempo operacional, por envolver as etapas de extração e determinação titulométrica do H +Al (Escosteguy \& Bissani, 1999); a subestimação dos teores de $\mathrm{H}+\mathrm{Al}$ em solos com pH na faixa de 6,5 a 7,0, decorrente do tamponamento deficiente do acetato de cálcio em sol os com esse grau de acidez (Raij, 1991).

Pela sua simplicidade e eficiência (Shoemaker et al., 1961), a solução tampão SMP tem sido, ultimamente, bastante utilizada nos laboratórios brasileiros na determinação da acidez potencial. Os estudos desenvolvidos por Quaggio et al. (1985), Corrêa et al . (1985), Sousa et al. (1989), Pavan et al . (1996), Maeda et al. (1997), Pereira et al. (1998), Gama et al. (1998) e Escosteguy \& Bissani (1999) comprovam a eficiência do métodoSMP para estimar a acidez potencial de solos oriundos de diferentes regiões e estados brasileiros. Todos esses estudos enfatizam o fato de ser o ajuste entre os teores de $\mathrm{H}+\mathrm{Al}$ e os valores de $\mathrm{pH}$ SMP influenciado por diferentes atributos dos solos, como textura e mineralogia, havendo uma variação bastante ampla nos diferentes componentes e model os de equação para os diferentes estados e regiões brasileiras (Maeda et al., 1997). Portanto, torna-se necessário o estabel ecimento de curvas de calibração específicas às diversas regiões, sobretudo para os solos de maior predominância na região.

Este estudo objetivou avaliar o grau de associação entre os teores de $\mathrm{H}+\mathrm{Al}$, determinados por titulometria, e os val ores de pH SMP, com vistas em estabelecer para laboratórios do N ordeste uma equação para estimar, de forma rápida e correta, a acidez potencial.

\section{MATERIAL E MÉTODOS}

Este estudo foi realizado nos laboratórios da Embrapa Solos. Foram escol hidas 81 amostras de solo $(0-20 \mathrm{~cm})$ oriundas dos estados nordestinos de Alagoas, Bahia, Ceará, Paraíba, Pernambuco e Rio Grande do N orte. Nas amostras desol os provenientes da coleção de solos da Embrapa Solos e de outros
Centros da Embrapa no Nordeste, os teores de carbono variaram de 1,8 a 35,6 $\mathrm{g} \mathrm{kg}^{-1}$ e os de argila de 60 a $590 \mathrm{~g} \mathrm{~kg}^{-1}$. Os valores de $\mathrm{pH}$ em água situaram-se na faixa de 4,39 a 7,30.

$\mathrm{O} \mathrm{H}+\mathrm{Al}$ foi extraído com acetato de cál cio a $0,5 \mathrm{~mol} \mathrm{L-1}, \mathrm{pH} 7,0$, e determinado por titulação com $\mathrm{NaOH} 0,025$ mol L-1. O procedimento analítico usado nas etapas de extração e quantificação do H +Al é descrito em Silva et al. (1998). O pH SMP foi determinado segundo Raij \& Quaggio (1983). Para obter o pH SMP das amostras de solo, foram colocados $10 \mathrm{~cm}^{3}$ deTFSA ( $2 \mathrm{~mm}$ ) em frasco plástico de $50 \mathrm{~mL}, 25 \mathrm{~mL}$ deágua destilada e $5 \mathrm{~mL}$ desolução tampãoSMP, agitando por 15 min, a 220 rpm. Após repouso por uma hora, procedeu-se à leitura do $\mathrm{pH}$ de equilíbrio da suspensão de solo com a solução tampão.

O grau de associação entre os valores médios de pH SMP e H + Al, obtidos de três repetições, foi determinado com o uso de "software" M icrosoft Excel 97, sendo escol hida a equação de melhor ajuste de acordo com o maior coeficiente de determinação.

\section{RESULTADOS E DISCUSSÃO}

Os valores de $\mathrm{pH}$ SMP variaram de 4,67 a 7,45, enquanto os de acidez potencial $(\mathrm{H}+\mathrm{Al})$, de 0 a $263,2 \mathrm{mmol}_{\mathrm{c}} \mathrm{dm}^{-3}$. Os valores de pH SMP e os teores de $\mathrm{H}+\mathrm{Al}$ no solo associaram-se inversamente, ou seja, a diminuição nos valores de pH SMP foi acompanhada por um aumento na concentração de $\mathrm{H}+\mathrm{Al}$. O modelo de equação que mel hor se ajustou aos dados obtidos foi oquadrático(Figura 1), chegandose à seguinte equação: $\mathrm{H}+\mathrm{Al}\left(\mathrm{mmol}_{\mathrm{c}} \mathrm{dm}^{-3}\right)=$ $31,521(\mathrm{pH}$ SMP) $2-451,61 \mathrm{pH}$ SMP $+1625,3$ $\left(R^{2}=0,87^{* *}\right)$. Essa equação permitiu estimar os valores de $\mathrm{H}+\mathrm{Al}$ a partir dos índices de $\mathrm{pH}$ SMP, para solos do Semi-Árido do Nordeste Brasileiro (Quadro 1).

O quadro 2, com a estimativa da acidez potencial de sol os de diferentes estados e regiões brasileiras, usando seis valores fixos de pH SMP, variando de 4,5 a 7,3, eequações relacionando H + Al com pH SMP, permitiu comparar os teores de $\mathrm{H}+\mathrm{Al}$ estimados para os sol os do Nordeste com os dos demais locais. No intervalo de pH SMP escolhido, os valores de acidez potencial estimados para os sol os do N ordeste apresentaram tendência similar àqueles obtidos para os sol os do Rio de J aneiro (Pereira et al., 1998), São Paulo (Quaggio et al., 1985), Minas Gerais (Corrêa et al., 1985) e Mato Grosso doSul (Maeda et al., 1997). No geral, os dados apresentados revelam que não houve, para um mesmo valor de pH SMP, similaridade nos valores obtidos para os solos analisados de diversos estados e regiões, demonstrando a influência dos atributos dos solos no seu tamponamento (Quadro 2). 
Quadro 1. Conversão de valores de pH SMP para acidez potencial $(\mathrm{H}+\mathrm{Al})$ para solos do SemiÁrido do Nordeste Brasileiro

\begin{tabular}{cccccc}
\hline pH SMP & H + Al & pH SMP & H + Al & pH SMP & H + Al \\
\hline & & & & & \\
& mmol $_{c} \mathrm{dm}^{-3}$ & & $\mathrm{mmol}_{\mathrm{c}} \mathrm{dm}^{-3}$ & & $\mathrm{mmol}_{\mathrm{c}} \mathrm{dm}^{-3}$ \\
4,65 & 206,9 & 5,55 & 89,8 & 6,45 & 23,8 \\
4,70 & 199,0 & 5,60 & 84,8 & 6,50 & 21,6 \\
4,75 & 191,3 & 5,65 & 79,9 & 6,55 & 19,6 \\
4,80 & 183,8 & 5,70 & 75,2 & 6,60 & 17,7 \\
4,85 & 176,4 & 5,75 & 70,7 & 6,65 & 16,0 \\
4,90 & 169,2 & 5,80 & 66,3 & 6,70 & 14,5 \\
4,95 & 162,2 & 5,85 & 62,1 & 6,75 & 13,1 \\
5,00 & 155,3 & 5,90 & 58,0 & 6,80 & 11,9 \\
5,05 & 148,5 & 5,95 & 54,1 & 6,85 & 10,8 \\
5,10 & 141,9 & 6,00 & 50,4 & 6,90 & 9,9 \\
5,15 & 135,5 & 6,05 & 46,8 & 6,95 & 9,2 \\
5,20 & 129,2 & 6,10 & 43,4 & 7,00 & 8,6 \\
5,25 & 123,1 & 6,15 & 40,1 & 7,05 & 8,1 \\
5,30 & 117,2 & 6,20 & 37,0 & 7,10 & 7,8 \\
5,35 & 111,4 & 6,25 & 34,0 & 7,15 & 7,7 \\
5,40 & 105,8 & 6,30 & 31,2 & 7,20 & 7,7 \\
5,45 & 100,3 & 6,35 & 28,6 & & \\
5,50 & 95,0 & 6,40 & 26,1 & & \\
& & & & & \\
\hline
\end{tabular}

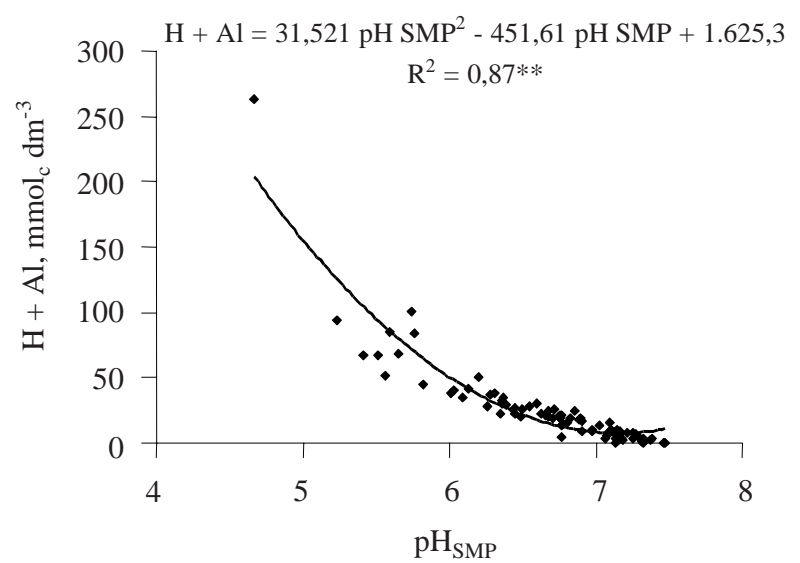

Figura 1. Relação entre a acidez potencial (H + Al) e o pH SMP, em solos do Semi-Árido do Nordeste Brasileiro.

A relação entre os valores médios de $\mathrm{H}+\mathrm{Al}$ $\left(\mathrm{mmol}_{\mathrm{c}} \mathrm{dm}^{-3}\right)$, apresentados no quadro 2 , e o pH SMP foi descrita pela seguinte equação: $\mathrm{H}+\mathrm{Al}=28,05$ $(\mathrm{pH} \text { SMP })^{2}-394,37 \mathrm{pH}$ SMP $+1400,4\left(\mathrm{R}^{2}=0,99 * *\right)$. Essa equação possibilitou estimar a acidez potencial para sol os de diversas regiões e estados brasileiros. Contudo, alguns pontos deveriam ser ainda ressaltados: (a) os valores de $\mathrm{H}+\mathrm{Al}$ estimados nos ramos extremos dessa curva mostraram-se bastante

Quadro 2. Estimativa dos teores de H + Al no solo, para valores de pH SMP na faixa de 4,5 a 7,3, por meio de equações ajustadas para diferentes estados e regiões brasileiros

\begin{tabular}{|c|c|c|c|c|c|c|c|}
\hline \multirow{2}{*}{ Região ou estado } & \multirow{2}{*}{ Referência(1) } & \multicolumn{6}{|c|}{ pH SMP } \\
\hline & & 4,5 & 5,0 & 5,7 & 6,0 & 6,8 & 7,3 \\
\hline & & \multicolumn{6}{|c|}{$\longrightarrow \mathrm{H}+\mathrm{Al}\left(\mathrm{mmol}_{\mathrm{c}} \mathrm{dm}^{-3}\right)$} \\
\hline Rio de J aneiro & Pereira et al. (1998) & 235,1 & 141,2 & 69,1 & 50,9 & 22,5 & 13,5 \\
\hline Rio G. do Sul e Santa Catarina & Escosteguy \& Bissani (1999) & 138,6 & 88,3 & 47,0 & 35,9 & 17,5 & 11,1 \\
\hline São Paulo & Quaggio et al. (1985) & 205,2 & 121,2 & 58,0 & 42,3 & 18,2 & 10,8 \\
\hline Paraná & Pavan et al. (1996) & 151,8 & 104,6 & 62,2 & 49,7 & 27,4 & 18,9 \\
\hline Nordeste Paraense & Gama et al. (1998) & 147,7 & 110,0 & 68,4 & 54,5 & 29,2 & 22,1 \\
\hline Minas Gerais & Correa et al. (1985) & 213,4 & 122,4 & 56,2 & 40,3 & 16,6 & 9,5 \\
\hline Mato Grosso do Sul & Maeda et al. (1997) & 273,0 & 160,5 & 76,3 & 55,5 & 23,7 & 14,0 \\
\hline Cerrados & Sousa et al. (1989) & 184,1 & 107,9 & 51,1 & 37,1 & 15,8 & 9,2 \\
\hline Nordeste & Presente trabalho & 231,5 & 155,3 & 75,2 & 50,4 & 11,9 & 8,3 \\
\hline Média & & 197,8 & 123,5 & 62,6 & 46,3 & 20,3 & 13,0 \\
\hline Desvio-padrão & & 43,2 & 22,9 & 9,8 & 7,0 & 5,4 & 4,4 \\
\hline Coeficiente de variação & & 21,8 & 18,5 & 15,6 & 15,2 & 26,7 & 33,9 \\
\hline
\end{tabular}

(1) As equações utilizadas para estimar os teores de $\mathrm{H}+\mathrm{Al}$ no solo foram: $\mathrm{RJ}: \mathrm{Ln}(\mathrm{H}+\mathrm{Al})=10,05-1,02 \mathrm{pH}$ SMP; RS e SC: H + Al = 7968,4(2,71828)-0,9004pHSMP; SP: Ln (H + Al) = 7,76-1,053 pH SMP; PR: Ln $(\mathrm{H}+\mathrm{Al})=6,068-0,744$ pH SMP; Nordeste Paraense: $\mathrm{H}+\mathrm{Al}=13,294(\mathrm{pH} \text { SMP) })^{2}-201,73 \mathrm{pH}$ SMP + 786,3; MG: Ln $(\mathrm{H}+\mathrm{Al})=8,06-1,111 \mathrm{pH}$ SMP; $M S$ : Ln $(\mathrm{H}+\mathrm{Al})=8,086-1,062 \mathrm{pH}$ SMP; Cerrados: $\operatorname{Ln}(\mathrm{H}+\mathrm{Al})=7,719-1,068 \mathrm{pH}$ SMP; Nordeste: $\mathrm{H}+\mathrm{Al}=31,521(\mathrm{pH} \text { SMP) })^{2}-451,61 \mathrm{pH}$ SMP + 1.625,3. 
imprecisos, pois os desvios-padrões acarretaram coeficientes de variação maiores que $20 \%$ (Quadro 2); (b) as incorreções foram maiores no ramo da curva onde os valores de pH SMP situaram-se em torno de 7,0. A utilização dessa curva para estimar a acidez potencial, principalmenteao usar os ramos extremos, suscitou uma série de preocupações, tais como: (1) a possibilidade de sub ou superestimar a CTC potencial; (2) a possibilidade de calcular, de forma errônea, a necessidade de calagem. A análise da figura 2 evidencia a necessidade de se obter, de forma regionalizada, a relação entre a acidez potencial e o pH SMP, visando minimizar os erros intrínsecos à determinação incor reta dos teores de H + Al do solo, considerando a importância desseatributo no cál culo de outras características que permitem a recomendação adequada de adubos e corretivos e, por conseguinte, influem no crescimento e desenvolvimento das plantas.

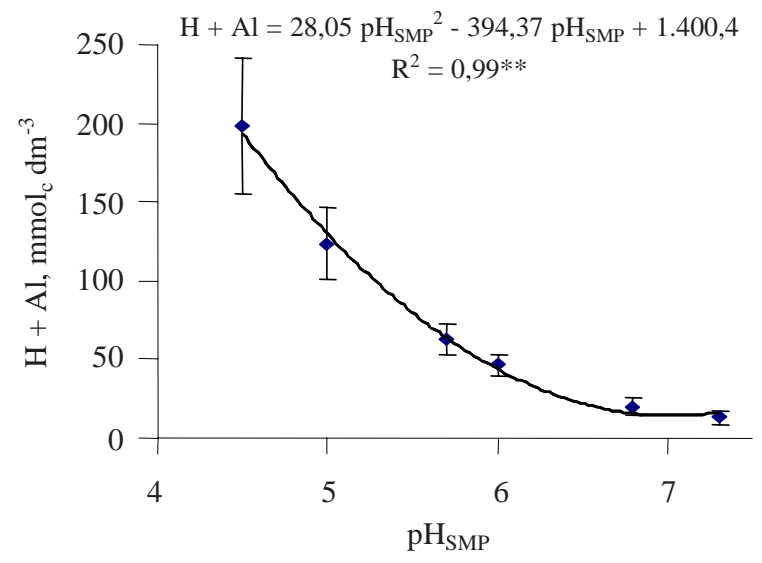

Figura 2. Relação entre os teores médios de $\mathrm{H}+\mathrm{Al}$, (Quadro 2) e o pH SMP, para solos de diversas regiões e estados brasileiros.

\section{CONCLUSÕES}

1. A equação $H+A I\left(m^{\prime} m_{c} \mathrm{dm}^{-3}\right)=31,521$ $(\mathrm{pH} \text { SMP })^{2}-451,61 \mathrm{pH}$ SMP $+1.625,3$ pode ser utilizada para estimar a acidez potencial de amostras de solos do Semi-Árido do Nordeste Brasileiro por meio de uma simples medição de pH SMP.

2. Comparações realizadas demonstraram a necessi dade de se ajustar, regional mente, a relação entre os teores de $\mathrm{H}+\mathrm{Al}$ e os índices de $\mathrm{pH}$ SMP, visto que a equação obtida com a média de dados de diferentes regi ões e estados do Brasil estima a acidez potencial de modo incorreto nos extremos da curva apresentada.

\section{LITE RATURA CITADA}

CORRÊA, J .B.; COSTA, P.C.; LOPES, A.S. \& CARVALHO, J .G. Avaliação de $\mathrm{H}+\mathrm{Al}$ pelo método SMP. In: CONGRESSO BRASILEIRO DE PESQUISAS CAFEEIRAS, 12., Caxambu, 1985. Anais. Rio deJ aneiro, Instituto Brasileiro do Café, 1985. p.111-112.

ESCOSTEGUY, P.A. \& BISSANI, C.A. Estimativa deH + Al pelo pH SMP em solos do Rio Grande do Sul edeSanta Catarina. R. Bras. Ci. Solo, 23:175-179, 1999.

GAMA, M.A.P.; PROCHNOW, L.I \& GAMA, J .R.N.F. Avaliação da acidez potencial pelo método do $\mathrm{pH}$ SMP em solos do Nordeste Paraense. In: RESUMOS DA FERTBIO, Caxambu, 1998. Anais. Lavras, Universidade Federal de Lavras, 1998. p.544

MAEDA, S.; KURIHRA, C.H.; HERNANI, L.C.; FABRICIO, A.C. \& SILVA, W.M. Estimativa da acidez potencial, pel o método do pH SMP, em solos do Mato Grosso do Sul. Dourados, Empresa Brasileira de Pesquisa Agropecária, 1997. 25p. (Boletim de Pesquisa, 3)

PAVAN, M.A.; OLIVEIRA, E.L. \& MIYAZAWA, M. Determinação indireta da acidez extraível do solo $(\mathrm{H}+\mathrm{Al})$ por potenciometria com a solução tampão SMP. Arq. Biol. Tecnol., 39:307-312, 1996.

PEREIRA, M.G.; VALLADARES, G.S.; SOUZA, J .M.P.F.; PÉREZ, D.V. \& DOS ANJ OS, L.H.C. Estimativa da acidez potencial pelo método do pH SMP em solos do estado do Rio de J aneiro. R. Bras. Ci. Solo, 22:159-162, 1998.

QUAGGIO, J .A.; RAIJ , B. van \& MALAVOLTA, E. Alternative use of the SMP-buffer solution to determine lime requirement of soils. Comm. Soil Sci. Plant Anal., 16:245260, 1985.

RAIJ , B. van \& QUAGGIO, J .A. Métodos de análise de solo para fins de fertilidade. Campinas, Instituto Agronômico, 1983. 31p. (Boletim Técnico, 81)

RAIJ , B. van. Fertilidade do solo e adubação. Piracicaba, Ceres/ Potafos, 1991. 343p.

SHOEMAKER, H.E.; MCLEAN, W.O. \& PRATT, P.F. Buffer methods for determining lime requiremet of soils with appreciable amounts of extractable aluminum. Proc. Soil Sci. Soc. Am., 25:274-277, 1961.

SILVA, F.C.; EIRA, P.A.; BARRETO, W.O.; PÉREZ, D.V. \& SILVA, C.A. Manual de métodos de análises químicas para avaliação da fertilidade do solo. Rio de J aneiro, Empresa Brasileira de Pesquisa Agropecária, 1998. 56p.

SOUSA, D.M.G.; MIRANDA, L.N.; LOBATO, E. \& CASTRO, L.H.R. Métodos para determinar as necessidades de calagem em solos dos cerrados. R. Bras. Ci. Solo, 13:193198, 1989. 